\title{
The Effects of Depression Severity on the Stress Coping Methods of Mothers with Mentally Disabled Children
}

\author{
(1) Sevda Bă̆ \\ University of Health Sciences Turkey, İstanbul Training and Research Hospital, Clinic of Psychiatry, İstanbul, Turkey
}

\begin{abstract}
Introduction: This study aimed to evaluate the effects of depression severity on stress coping methods of mothers with mentally disabled children.

Methods: This study included 50 mothers of children with intellectual disabilities who were admitted to the psychiatric outpatient clinic of our hospital. Sociodemographic data form, Beck Depression scale, and Stress Coping scale were applied to all participants.

Results: The mean Beck Depression score of participants was $17.42 \pm 6.32$. A One-Way relationship was found between the Beck Depression score and Stress Coping scale-desperate and submissive subscales. The Stress Coping Scale-desperate approach score is higher in those with severe depression than those with mild depression, whereas the Stress Coping scale-self-confidence subscale is higher in those with severe depression. The Stress Coping scale-submissive approach score is higher in participants with moderate depression than those with mild depression $(p<0.005)$.

Conclusion: Depression negatively affects the stress coping methods of mothers with children with intellectual disabilities, and psychosocial support is recommended to be provided to mothers who prefer desperate and submissive approaches to stress management methods.
\end{abstract}

Keywords: Disabled children, coping stress, submissive approach, desperate approach, depression

\section{Introduction}

Mental disability, also known as mental retardation, is a chronic problem that is observed in 2-3\% of the total population and can be determined by the deterioration in various sub-dimensions of intelligence, such as cognition, language, motor, and social skills (1). It occurs in early childhood and is characterized by a decreased ability to adapt to the environment. Mental abilities, in general, are significantly below average. In most cases, intellectual disability is a very frustrating life condition with no real cure (2). The emotional burden on families begins to increase as soon as they learn that they have a child with a mental disability. A healthy child is expected; however, the birth of a child with different characteristics significantly affects the life of the family. In the first stage, families respond by ignoring and denying, and then the grieving process begins. In the grieving process, feelings of intense sadness and helplessness accompany the feelings of guilt (3). When caring for a disabled child, family problems, such as jealousy among siblings and neglect of the other child, also arise with other children in the family (4). Finally, marital relations are broken. Numerous studies revealed communication problems (5) between the presence of a disabled child in the family and the parents, thus families may experience feelings, such as anger, guilt, relationship problems, and unhappiness. In addition to family problems, social problems can be experienced, such as social problems and exclusion.

Moreover, mothers who take care of the needs of the disabled child on one hand and protect the child from dangers, on the other hand, experience increased stress levels. The mother takes care to meet the needs of both the disabled child and other family members.

Additionally, the decreased participation in social activities due to the attitudes and judgments of the society toward disability and the uncertainty of the child's present and future situation causes more anxiety in the mothers. Thoughts about the future life of children and who will take care of their children when they are unavailable increase their anxiety. Therefore, social and emotional problems, such as social isolation, depression, guilt, and anxiety, may occur in mothers of disabled children.

Especially in society, the child is considered as the personal success or failure of the mother. A sick child may be seen as a failed child, thus the mother may be blamed or even humiliated by the mother's environment. This situation affects the mother's feelings and may cause the mother 
to experience more guilt, dissatisfaction, and stress compared to other family members (6). The severity of anxiety and depression experienced by mothers can change their coping mechanisms (7). Stress coping methods also affect the child care process. Therefore, this study aimed to investigate the effects of depression on the stress coping methods of mothers with mentally retarded children.

\section{Methods}

This study included 50 mothers with mentally retarded children who agreed to participate in the study. A sociodemographic data form including age, education level, marital status, age of the mentally disabled child, and the total number of children was evaluated. Additionally, the mothers were evaluated using the Beck Depression scale (BDS) and the Stress Coping scale, Stress Coping scale subscales of mothers with high scores on the BDS were compared with the Stress Coping subscale results of mothers without depression. Approval was obtained from the Ethics Committee of University of Health Sciences Turkey, İstanbul Training and Research Hospital (approval number: 2949, date: 22.10.2021). Consent was obtained from all participants.

\section{Stress Coping Scale}

The scale consisted of 30 items, wherein the total score is not calculated, but the scores for each factor are separately calculated. The high scores obtained from the subscales indicate that the approach in that subscale is used more in coping with stress. In the evaluation of the scale, as the scores obtained from the factors of Self-Confidence, Optimism, and Seeking Social Support increase, stress coping was found effective. The increased scores obtained from the desperate approach and submissive approach factors indicate that ineffective methods are used in stress coping (8).

\section{BDS}

BDS is a self-report scale that is developed by Beck in 1961 to measure the emotional, cognitive, somatic, and motivational components. The validity and reliability of the BDS, which is used to determine the intensity of depression, was determined by Teğin (9) for the Turkish population.

\section{Statistical Analysis}

Statistical analyzes were performed using the Statistical Package for the Social Sciences version 17.0 program. The conformity of variables to the normal distribution was examined using histogram graphics and the Kolmogorov-Smirnov test. Mean, standard deviation, median, and minimum-maximum values were used while presenting descriptive analyzes. Comparisons between more than two groups were made using the Kruskal-Wallis test, and post-hoc analyzes were made using the Mann-Whitney U test. The Spearman correlation test was used in the analysis of the measurement data with each other. P-values of $<0.05$ were considered statistically significant.

\section{Results}

The mean age of participants in the study was $42.62 \pm 9.73$ years. The minimum age was 25 , and the maximum age was 59 years. Of the participants, 20 are at primary education level, 26 at high school, and 4 at the university education level. Additionally, 24 participants are working and 26 are housewives. The mean duration of marriage was $14.26 \pm 7.64$ years. The mean age of the disabled child was 11.14 \pm 4.16 years and the mean number of children was $2.16 \pm 0.74$. Mild Beck Depression score was determined in 25 participants, moderate in 22, and severe in 3 people. The mean Beck Depression score was 17.42 \pm 6.32 . The mean Coping with Stress scale-Helpless Approach Subscale score was 17.88 \pm 5.27 , Submissive Approach was 14.78 \pm 4.01 , self-confidence was 16.32 \pm 3.80 , Seeking Social Support Approach was 11.78 \pm 2.57 , and

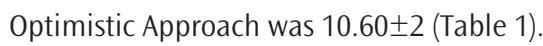

The relationship between the Beck Depression score and Coping With Stress subscales and age, duration of the marriage, age of the disabled child, and the number of children were examined. An inverse relationship was found between age and the Coping with Stress scaleOptimistic Approach subscale. As the age of the mother progresses, the optimistic approach method also decreases. A statistically significant relationship was found between the age of the disabled child and the Stress Coping scale-Social Support Seeking Approach subscale. As the age of the child increases, the help-seeking behavior also increases. A statistically significant relationship was found between the number of children and the Stress Coping scale-self-confidence subscale (Table 2). Education levels, Beck Depression score, and Coping with Stress subscales were compared and revealed no significance $(p>0.05)$ (Table 3).

The relationship between the Beck Depression score and Coping with Stress subscales was investigated. A significant relationship was found

\begin{tabular}{|c|c|c|c|}
\hline \multicolumn{4}{|r|}{$\begin{array}{l}\text { Median } \\
\text { (min.-max.)-\% }\end{array}$} \\
\hline \multicolumn{2}{|l|}{ Age } & $42.62 \pm 9.73$ & $45(25-59)$ \\
\hline \multirow{3}{*}{ Education } & Primary school & 20 & $(40.00)$ \\
\hline & High school & 26 & $(52.00)$ \\
\hline & University & 4 & $(8.00)$ \\
\hline \multirow{2}{*}{ Work } & House wife & 26 & $(52.00)$ \\
\hline & Working & 24 & $(48.00)$ \\
\hline \multicolumn{2}{|c|}{ Years of marriage } & $14.26 \pm 7.64$ & $14.50(1-30)$ \\
\hline \multicolumn{2}{|c|}{ Age of disabled child } & $11.14 \pm 4.16$ & $10.50(2-22)$ \\
\hline \multicolumn{2}{|c|}{ Number of children } & $2.16 \pm 0.74$ & $2(1-3)$ \\
\hline \multirow{3}{*}{ Beck } & Mild & 25 & $(50.00)$ \\
\hline & Moderate & 22 & $(44.00)$ \\
\hline & Severe & 3 & $(6.00)$ \\
\hline \multicolumn{2}{|c|}{ Beck Depression score } & $17.42 \pm 6.32$ & $16(10-33)$ \\
\hline \multicolumn{2}{|c|}{$\begin{array}{l}\text { Coping with Stress scale - Desperate } \\
\text { approach }\end{array}$} & $17.88 \pm 5.27$ & $17.50(10-30)$ \\
\hline \multicolumn{2}{|c|}{$\begin{array}{l}\text { Coping with Stress scale - Submissive } \\
\text { approach }\end{array}$} & $14.78 \pm 4.01$ & $13.50(10-23)$ \\
\hline \multicolumn{2}{|c|}{ Coping with Stress scale - Self-confidence } & $16.32 \pm 3.80$ & $16(10-25)$ \\
\hline \multicolumn{2}{|c|}{$\begin{array}{l}\text { Coping with Stress scale - Seeking Social } \\
\text { Support }\end{array}$} & $11.78 \pm 2.57$ & $12(5-16)$ \\
\hline \multicolumn{2}{|c|}{ Coping with Stress scale - Optimism } & $10.60 \pm 2.84$ & $10(5-15)$ \\
\hline
\end{tabular}


between the Beck Depression score and the Stress Coping scale-Helpless Approach and Submissive Approach subscale (Table 4). This result revealed that mothers with depression prefer to use ineffective methods of coping with stress $(p<0.05)$.

Coping With Stress subscales were compared according to Beck Depression Severity. Those with severe Beck Depression have a higher Coping with Stress scale-Helpless Approach subscale than those with mild Beck Depression, and a lower self-confidence subscale score than those with mild depression. Stress Coping scale-Submissive Approach subscale score was higher in those with moderate Beck Depression status than those with mild Beck Depression status (Table 5) $(p<0.05)$.

\section{Discussion}

This study aimed to determine the relationships between the stress levels caused by the depression level of mothers with disabled children and the variables of coping styles, such as self-confident approach, optimistic approach, self-blaming approach, submissive approach, and social support seeking approach.

Having a child with an intellectual disability is stressful. Stress, depression, and anxiety levels of mothers were also revealed as high in

\begin{tabular}{|c|c|c|c|c|c|}
\hline & & Age & $\begin{array}{l}\text { Years of } \\
\text { marriage }\end{array}$ & $\begin{array}{l}\text { Age of the } \\
\text { disabled } \\
\text { child }\end{array}$ & $\begin{array}{l}\text { Number of } \\
\text { children }\end{array}$ \\
\hline \multirow{2}{*}{ Beck Depression scores } & $r$ & 0.138 & 0.022 & 0.116 & -0.098 \\
\hline & $p$ & 0.341 & 0.882 & 0.421 & 0.500 \\
\hline \multirow{2}{*}{$\begin{array}{l}\text { Coping with Stress scale } \\
\text { - Desperate approach }\end{array}$} & $r$ & -0.128 & -0.140 & 0.040 & -0.228 \\
\hline & $p$ & 0.377 & 0.333 & 0.783 & 0.111 \\
\hline \multirow{2}{*}{$\begin{array}{l}\text { Coping with Stress scale } \\
\text { - Submissive approach }\end{array}$} & $r$ & -0.054 & -0.048 & -0.074 & -0.134 \\
\hline & $p$ & 0.711 & 0.739 & 0.610 & 0.355 \\
\hline \multirow{2}{*}{$\begin{array}{l}\text { Coping with Stress scale } \\
\text { - Self-confidence }\end{array}$} & $r$ & -0.052 & -0.055 & 0.197 & 0.314 \\
\hline & $\mathrm{p}$ & 0.719 & 0.705 & 0.170 & 0.026 \\
\hline \multirow{2}{*}{$\begin{array}{l}\text { Coping with Stress } \\
\text { scale - Seeking Social } \\
\text { Support }\end{array}$} & r & -0.173 & -0.098 & 0.326 & -0.207 \\
\hline & $\mathrm{p}$ & 0.228 & 0.499 & 0.021 & 0.149 \\
\hline \multirow{2}{*}{$\begin{array}{l}\text { Coping with Stress scale } \\
\text { - Optimism }\end{array}$} & $r$ & -0.325 & -0.205 & 0.099 & -0.031 \\
\hline & p & 0.021 & 0.154 & 0.495 & 0.831 \\
\hline
\end{tabular}

many studies in the literature (10). Due to her cultural role in society, women are responsible for chores, such as housework and childcare. With the effects of this situation, the burden of mothers with a disabled child also increases compared to fathers (11). All participants in our study had depression, $50 \%$ of ratıo had at least mild depression. This result supports the results from previous studies. Many studies revealed that mothers' stress, depression, and anxiety levels are higher than fathers' (12). Therefore, mothers were preferred in our study. The relatively high level of fathers' stress can also be interpreted as a result of the economic burden caused by the disease. Some studies revealed no relationship between parental stresses (13).

Additionally, studies revealed that as the age of the disabled child increases, the depression symptoms of the parents increase, and the depression levels of the parents who have children aged 7 years and over are higher than the depression levels of the parents who have children between the ages of 0 and 6 years (14). The possible reason is that special education is taken with the advancing age, in addition to the periods that affect the family, such as adolescence, thus the burden on the family increases even more. Our study revealed no correlatıon between maternal depression and the age of children. Additıonally, the social seeking support subscale correlated as the child gets older

Coping is an individual's response to stressful situations. Difficulties may arise with the care of the child in mental or physical developmental delays; however, appropriate coping methods are stated to play a role in protecting the parents from the effects of a challenging situation (15). Problem-focused coping methods are generally used with positive expectations.

Therefore, the subscales of the Stress Coping scale in our study revealed that as the mother's depression increased, the helpless approach

\begin{tabular}{l|l|l|}
$\begin{array}{l}\text { Table 4. Spearman Correlation test-Relations with Coping with } \\
\text { Stress scale subscales and depression }\end{array}$ \\
\begin{tabular}{l|l|l|} 
Coping with Stress scale \\
subscales
\end{tabular} & Beck Depression scale \\
\hline Desperate approach & r & p \\
\hline Submissive approach & 0.438 & 0.001 \\
\hline Self-confidence & -0.243 & 0.001 \\
\hline Seeking social support & -0.144 & 0.089 \\
\hline Optimistic approach & -0.075 & 0.319 \\
\hline
\end{tabular}

Table 3. Education level and depression and coping stress scale relation

\begin{tabular}{|c|c|c|c|c|c|c|c|}
\hline & \multicolumn{6}{|l|}{ Education } & \multirow{3}{*}{$\mathbf{p}$} \\
\hline & \multicolumn{2}{|c|}{ Primary school } & \multicolumn{2}{|l|}{ High school } & \multicolumn{2}{|l|}{ University } & \\
\hline & Mean \pm SD & Median & Mean \pm SD & Median & Mean \pm SD & Median & \\
\hline Beck depression scores & $18.30 \pm 6.39$ & 18.50 & $16.96 \pm 6.48$ & 13.00 & $16.00 \pm 5.83$ & 15.50 & 0.628 \\
\hline \multicolumn{8}{|l|}{ Coping with Stress scale } \\
\hline Desperate approach & $18.95 \pm 5.49$ & 19.50 & $16.85 \pm 4.91$ & 15.00 & $19.25 \pm 6.50$ & 21.00 & 0.311 \\
\hline Submissive approach & $14.60 \pm 4.15$ & 13.00 & $14.35 \pm 3.86$ & 13.00 & $18.50 \pm 3.00$ & 20.00 & 0.183 \\
\hline Self-confidence & $16.40 \pm 3.94$ & 16.00 & $16.12 \pm 3.40$ & 16.00 & $17.25 \pm 6.34$ & 17.00 & 0.906 \\
\hline Seeking social support & $11.65 \pm 2.48$ & 11.50 & $11.77 \pm 2.29$ & 11.50 & $12.50 \pm 5.00$ & 15.00 & 0.594 \\
\hline Optimism & $11.05 \pm 1.79$ & 10.50 & $10.00 \pm 3.09$ & 9.00 & $12.25 \pm 4.86$ & 14.50 & 0.088 \\
\hline
\end{tabular}




\begin{tabular}{|c|c|c|c|c|c|c|c|}
\hline \multirow{3}{*}{ Coping with Stress scale subscales } & \multicolumn{6}{|l|}{ Beck } & \multirow{3}{*}{$\mathbf{p}$} \\
\hline & \multicolumn{2}{|l|}{ Mild } & \multicolumn{2}{|l|}{ Moderate } & \multicolumn{2}{|l|}{ Severe } & \\
\hline & Mean \pm SD & Median & Mean \pm SD & Median & Mean \pm SD & Median & \\
\hline Desperate approach & $15.92 \pm 4.30$ & 15.00 & $18.77 \pm 4.90$ & 19.00 & $27.67 \pm 2.52$ & 28.00 & 0.004 \\
\hline Submissive approach & $13.20 \pm 3.30$ & 12.00 & $16.23 \pm 4.10$ & 16.00 & $17.33 \pm 4.62$ & 20.00 & 0.018 \\
\hline Seeking social support & $12.08 \pm 2.43$ & 12.00 & $11.59 \pm 2.87$ & 11.00 & $10.67 \pm 1.15$ & 10.00 & 0.436 \\
\hline Optimistic approach & $10.80 \pm 3.18$ & 10.00 & $10.55 \pm 2.63$ & 10.00 & $9.33 \pm 0.58$ & 9.00 & 0.616 \\
\hline
\end{tabular}

and submissive approach subscale scores of the Stress Coping scale increased. This result is important in terms of showing the problems of depression in mothers in stress coping brought on by the mentally handicapped child.

Studies revealed that the family's ability to cope increases as the education level of the family increases (16). No significant difference was found between the subscales with the increased educational level in our study.

Families become inadequate in coping with the long-lasting and wearing problem and may experience various emotional and behavioral problems. The most important of these problems is depression, which significantly affects the mother's life. Supporting the mothers from a psychiatric point of view is important since this situation will complicate the care of the child, among other difficulties. Our study supports the results of previous studies.

\section{Study Limitations}

This study has a small number of mothers with mentally handicapped children since mothers undertake the care of children with disabilities alone and therefore cannot find time to apply to our polyclinic. The difficulties of the participants in finding a person to care for their children reduced the number of participants in our study and caused a decreased number of participants.

\section{Conclusion}

Our results revealed that as the age of the children with a mental disability grows, the social support seeking approach in mothers increases. Additionally, having a mentally disabled child causes anxiety for the future and depression for mothers, and causes the mother to wear out, leading to negative stress coping methods. Our study revealed the necessity of determining the severity of depression in mothers of mentally retarded children and supporting them in the psychiatric field. We recommend providing psychosocial support and applying psychiatric treatments that address the family as a whole to correct this situation.

Ethics Committee Approval: Approval was obtained from the Ethics Committee of University of Health Sciences Turkey, İstanbul Training and Research Hospital (approval number: 2949, date: 22.10.2021).

Informed Consent: Consent was obtained from all participants.
Peer-review: Externally peer-reviewed.

Financial Disclosure: The author declared that this study received no financial support.

\section{References}

1. Abasiubong F, Obembe A, Ekpo M. A controlled study of anxiety and depression in mothers of children with learning disability in Lagos, Nigeria. Niger J Med 2006; 15: 124-7.

2. Witt WP, Riley AW, Coiro MJ. Childhood functional status, family stressors, and psychosocial adjustment among school-aged children with disabilities in the United States. Arch Pediatric Adolescent Med 2003; 157: 687-95.

3. Ciğerli Ö, Topsever P, Alvur TM, Görpelioğlu S. parental experiences since the diagnosis of disability in families with a disabled child: accepting the difference. TJFMPC 2014; 8: 86-92.

4. Sanders JL, Morgan SB. Family stress and adjustment as perceived by parents of children with autism or Down Syndrome: Implications for intervention. Child \& Family Behavior Therapy 1996;19: 15-32.

5. Köksal G, Kabasakal Z. The examination of predıctıng factors of perceived stress of parents with mental retarded children. Buca Eğitim Fakültesi Derg 2012; 32: 71-91.

6. Dereli F, Okur S. Determination of the depression level of the families having a handicapped child. Yeni Tıp Derg 2008; 25: 164-8.

7. Hamlyn-Wright S, Draghi-Lorenz R, Ellis J. Locus of control fails to mediate between stress and anxiety and depression in parents of children with a developmental disorder. Autism 2007; 11: 489.

8. Şahin NH, Durak A. A Brief Coping Styles Inventory For University Students. Türk Psikoloji Derg 1995; 10: 56-73.

9. Tegin B. Cognitive processes in depression, according to the Beck model examination. Journal of Psychology 1987; 6: 116-21.

10. Deniz ME, Dilmaç B, Arıcak OT. An analysis of life satisfaction and state-trait anxiety of the parents with handicapped children. International Journal of Human Sciences; 2009; 6: 953-68.

11. Gray DE. Coping over time: the parents of children with autism. J Intellect Disabil Res 2006; 50: 970-6. 
12. Kaner S. Perceived stress, social support and life satisfaction in parents with disabled children. Ankara University: Scientific Research Project Final Report; 2004; p. 7-67.

13 Illhan T. Parents of 3-6 year old children with special needs relationship between their levels and their roles. Ankara University Education Faculty of Special Education Journal; 2017; 18: 383-400.

14. Küllü Z. Depression status in parents of disabled children evaluation, Unpublished Master's Thesis. Kayseri: Erciyes University Institute of Health Sciences; 2008.
15. Oğuzhan M, Erden G. Children with chronic and fatal diseases and the problems that arise in their families and psychosocial intervention importance. New Symposium Journal 2012; 3: 167-7.

16. Ayyildiz T, Șener DK, Kulakçı H, Veren F. Evaluation of stress coping methods of mothers with mentally retarded children. Health Services Journal 2012; 11: 1-12. 